\title{
Analytical Study of Clinicopathological Data of Saudi Patients with Osteoarthritis Subjected to Total Knee Arthroplasty
}

\author{
Estudio Analítico de Datos Clínico-Patológicos de Pacientes Sauditas \\ con Osteoartritis Sometidos a Artroplastia Total de Rodilla
}

\author{
Gamal S. Abd El-Aziz ; Wafaey Gomaa ${ }^{2,4}$; Adel Hegaze²; Hesham N. Mustafa ${ }^{1}$ \& Amr Al-Hibshi
}

ABD EL-AZIZ, G. S.; GOMAA, W.; HEGAZE, A.; MUSTAFA, H. N. \& AL-HIBSHI, A. Analytical study of clinicopathological data of Saudi patients with osteoarthritis subjected to total knee arthroplasty. Int. J. Morphol., 37(3):1089-1094, 2019.

SUMMARY: Knee osteoarthritis (OA) is a common disabling disease. Epidemiological studies have revealed various risk factors for OA, including sex, aging, obesity, occupational illnesses, and chronic diseases. Here we evaluate the clinical, pathological, and radiological findings of knee OA in a subset of Saudi patients who were subjected to total knee replacement (TKA). The study population included 30 Saudi patients with knee OA who were operated by TKA (from June 2014 to December 2015) in the Department of Orthopedics, Faculty of Medicine, King Abdulaziz University, Saudi Arabia. Patient's clinical and radiological data were collected from the hospital files. Pathological examination of the excised superior articular surface of tibia and femoral condyles were done. Pearson Chi-squared analysis was used to test for differences between the variables in associated risk factors. There were more women than men. Sixty per cent of patients were older than 60 years [mean age, 59.2 (females) and 61.7 (men) years-old]. All patients exceeded obesity class 1 , with females being more obese than males. Pathological examination of the superior articular surface of tibia and femoral condyles showed high score lesions, which was more apparent in females than in males. Radiological findings showed that most lesions were high grade. The findings of this study will help to understand the pathogenesis of OA and improve treatment decision making relevant to TKA in knee OA in Saudi Arabia and elsewhere.

KEY WORDS: Osteoarthritis; Knee; Arthroplasty.

\section{INTRODUCTION}

Osteoarthritis $(\mathrm{OA})$ is a progressive degenerative disease of the synovial joints in which the articular cartilage and the adjacent subchondral bone show the most noticeable changes. OA is a major cause of impaired mobility, pain, disability, and reduced quality of life (Zeni \& SnyderMackler, 2010). Knee OA is the most prevalent form all over the world. The prevalence of knee OA ranges from 3.8-70 $\%$. This large range might be due to differences in race, lifestyle or socioeconomic background (Murphy \& Helmick, 2012). Epidemiological studies have identified risk factors for knee OA, including aging, obesity, and overuse of the joints, especially in certain occupations. Knee OA treatment is initially conservative, such as physiotherapy, lifestyle change, and medical drugs in the form of non-steroidal antiinflammatory drugs or other herbal medicine (Kingsbury et al., 2013). Total knee arthroplasty (TKA) is necessary for those patients in which a conservative treatment fails. The occurrence of OA among Saudi people is reported to be 13
$\%$, but this can reach $30-60 \%$ in selected regions (Al-Arfaj et al., 2003).

There is a paucity of research that correlates patients' data and radiological findings with pathological findings. This study was designed to correlate demographic factors (age, gender, obesity, and comorbidities) with pathological and radiological findings in Saudi patients who were treated by TKA. Such correlations will help plan surgical intervention in knee OA and to evaluate the outcomes.

\section{MATERIAL AND METHOD}

Patients. The study population included 30 Saudi knee OA patients who were diagnosed in the period from June 2014 to December 2015 and treated with TKA at the Department

\footnotetext{
${ }^{1}$ Department of Anatomy, Faculty of Medicine, King Abdulaziz University, Jeddah, Saudi Arabia.

${ }^{2}$ Department of Orthopaedics, Faculty of Medicine, King Abdulaziz University, Jeddah, Saudi Arabia.

${ }^{3}$ Department of Pathology, Faculty of Medicine, King Abdulaziz University, Jeddah, Saudi Arabia.

${ }^{4}$ Department of Pathology, Faculty of Medicine, Minia University, Al Minia, Egypt.
} 
of Orthopaedics, Faculty of Medicine, King Abdulaziz University, Jeddah, Saudi Arabia. Patient's data was collected from the hospital archive. The body mass index (BMI) was calculated using the standard formula (weight/height2). Plain radiographs of the patients were examined and graded according to the Kellgren/Lawrence $(\mathrm{K} / \mathrm{L})$ grading system (Kellgren \& Lawrence, 1957), using the following grades: grade 0 , normal; grade 1 , doubtful narrowing of joint space and possible osteophytes only; grade 2, definite osteophytes and definite joint space narrowing; grade 3 , moderate multiple osteophytes, definite joint space narrowing, some severe sclerosis, and possible deformity of bone contour; and grade 4, large osteophytes, severe joint space narrowing, severe bony sclerosis, and definite deformity of bone. Definite radiographic knee OA was defined on the K/L scale as grade $\geq 2$, and the final grade assigned to a patient's radiograph was the highest grade for the most severely affected knee.

The decision to progress to TKA was taken on the basis of the following criteria: failure of conservative treatment, disturbance of daily life activities, continuous pain (especially night pain), and marked joint limitation of movements. All patients gave informed consent to participate in this study and were recruited on a volunteer basis. This study was approved by the Unit of Biomedical Ethics Research Committee in Faculty of Medicine, King Abdulaziz University. In the TKA, all patients received a femoralcrucial retaining cemented femoral implant; tibial tray fixed bearing modular cocr (Sigma, DePuy, and polyethylene tibial insert fixed bearing curved Johnson \& Johnson Company Fixation of the tibial and femoral components was done with cement. The articulating surface of the patella was refined.

Pathological examination. The articular cartilages from the excised superior articular surface of tibia and femoral condyles were grossly examined for location and shape of lesions on the superior articular surface of tibia and femoral condyles. The lesions were evaluated as the percent of cartilage surface affected (Vignon et al., 1987). Macroscopic scores were as follows; score 0 (cartilage surface is smooth and normal in color), score 1 (cartilage surface is rough with minimal fibrillation or slight yellow discoloration), score 2 (cartilage erosion extending into superficial or medial layers), score 3 (cartilage erosion extending into deep layers), and score 4 (complete cartilage erosion with subchondral bone exposure) (Hongbin et al., 2004). The areas showing the damaged cartilage were cut into 2-mm thick slices, including a rim of the subchondral bone, and processed for histological examination. Sections were stained with Safranin O with Light Green counter-stain (Kang et al., 2003). Sections were examined and graded based on the most advanced state of $\mathrm{OA}$ in the section, irrespective of whether osteophytes were present (Pritzker et al., 2006). For statistical purposes, grades $0,1,2$, and 3 were considered low-grade microscopic changes. On the other hand, grades 4, 5, and 6 were considered high-grade changes.

Statistical analysis. The Pearson Chi-squared analysis was used to test for differences between the variables in associated risk factors. Statistical significance was set at a level of $p \leq 0.05$ and was two-sided. Statistical analysis of the data was performed using SPSS 23 for Windows.

\section{RESULTS}

Patients' observations. As shown in Tables I and II, in this study, most of the OA patients who were subjected to TKA were female $(86.7 \%)$. Of the included patients, $60 \%$ were more than 60-years-old. In the females, the mean age was 59.23 years (range, $48-71$ years), while in males, the mean age was 61.75 years (range, 60-63 years). All patients exceeded the healthy BMI with the majority of patients in obesity class $1(50 \%)$ or $2(40 \%)$. The mean BMI value was higher in females (35.9) than in males (30.5).

Radiological data. The scores of the radiological examination of patients' $\mathrm{X}$-rays are listed in Table III, with representative examples shown in Figure 3. All lesions belonged to grades $3(26.7 \%)$ or 4 (73.3). In the male patients, half of the lesions were score 3 and half score 4 . In the female patients, most lesions belonged to score 4 (76.9), with the remaining as score $3(23.1 \%)$. Correlation with BMI and pathological findings revealed no statistical significance (Table IV).

Pathological findings. The scores of the gross features are listed in Table III with representative examples shown in Figure 1. Observation of the superior articular surface of tibia and femoral condyle in all patients revealed that most lesions belonged to score 1 or 2 , with few score 4 lesions among our patients. In the male patients, most lesions belonged to scores 1 or 3 (50\% for each), with no score 2 or 4 lesions were identified. In the female patients, the lesion scores were (in descending order) score 2 (38.5\%), 1 (30.8 $\%), 3(15.4 \%)$ or $4(15.4 \%)$. The scores of the microscopic features are listed in Table III with representative examples shown in Figure 2. By histological examination, most lesions were graded high $(67.7 \%)$, with the remainder graded as low $(33.3 \%)$. In the male patients, $75 \%$ of the lesions were high grade (25\% low grade). In the female patients, $65.6 \%$ of the lesions were high grade ( $34.4 \%$ low grade). Moreover, we detected an association between macroscopic and microscopic grades $(\mathrm{p}=0.001)$. 

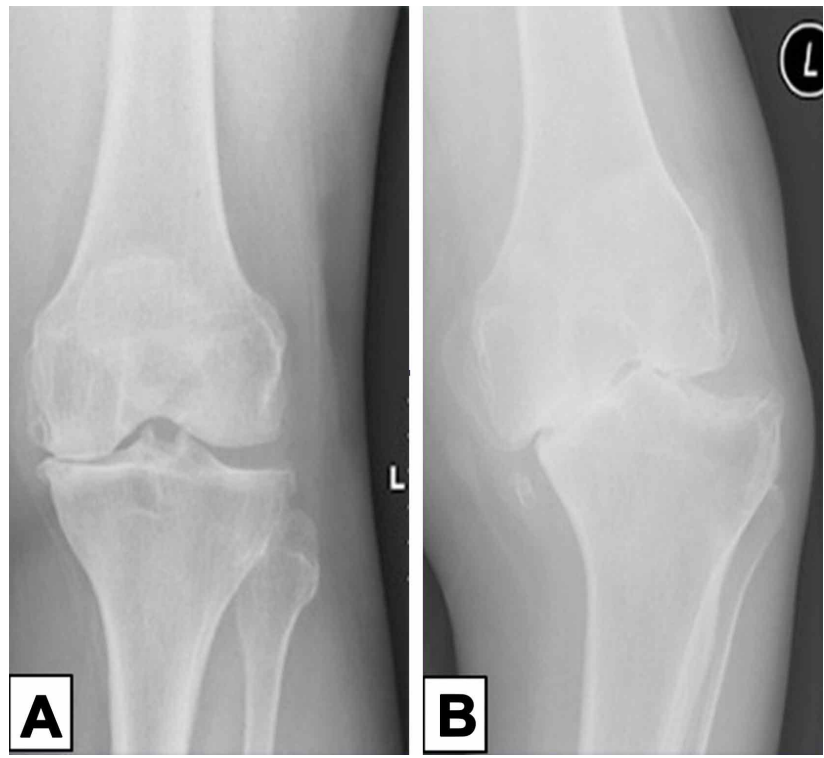

Fig. 1. A: Plain X-Ray of knee joint showing marked narrowing of medial joint space, osteophyte formation, and sclerosis. B: Plain XRay of knee joint showing marked osteoarthritic changes with obliteration of joint space, multiple osteophytes, and varus deformity.

Table I. Patient features.

\begin{tabular}{llc}
\hline & Parameters & $\mathrm{n}(\%)$ \\
\hline Sex & Male & $4(13.3 \%)$ \\
\multirow{2}{*}{ Age } & Female & $26(86.7 \%)$ \\
& $<60$ & $18(60 \%)$ \\
Operative Side & $\geq 60$ & $12(40 \%)$ \\
& Unilateral & $28(93.7 \%)$ \\
BMI & Bilateral & $2(6.7 \%)$ \\
& Normal BMI & $0(0 \%)$ \\
& Overweight & $1(3.3 \%)$ \\
& Obesity class 1 & $15(50 \%)$ \\
& Obesity class 2 & $12(40 \%)$ \\
& Morbid obesity & $2(6.7 \%)$ \\
\hline
\end{tabular}

BMI: Body Mass Index.
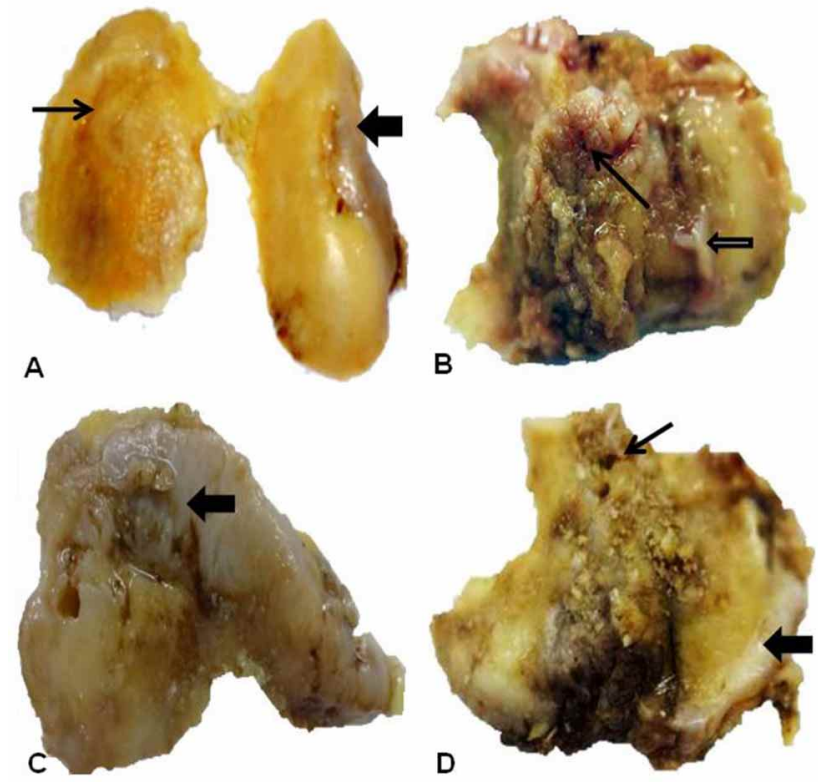

Fig. 2. Gross photographic images of various osteoarthritic lesions. A: Pieces of femoral condyle cartilage showing superficial erosion of cartilage (thin arrow) \{macroscopic score 2$\}$ and residual normal cartilage (thick arrow). B: Tibial condylar cartilage showing deep fissures \{macroscopic score 3$\}$ (thin arrow) with normal cartilage plate (thick arrow). C: Femoral condylar cartilage showing deep fissures \{macroscopic score 3 \} (thin arrow). D: Cartilage denudation with reparative tissue on the surface (thin arrow).

Table III. The percentages of the macroscopic scores, microscopic, and radiological grades among our patients.

\begin{tabular}{lcccccccccc}
\hline & \multicolumn{3}{c}{ Macroscopic score } & \multicolumn{4}{c}{ Microscopic grade } & \multicolumn{3}{c}{ Radiological grade } \\
& 1 & 2 & 3 & 4 & Low & High & 1 & 2 & 3 & 4 \\
\hline All patients & $33.3 \%$ & $33.3 \%$ & $20 \%$ & $13.4 \%$ & $33.3 \%$ & $67.7 \%$ & $0 \%$ & $0 \%$ & $26.7 \%$ & $73.3 \%$ \\
Males & $50 \%$ & $0 \%$ & $50 \%$ & $0 \%$ & $25 \%$ & $75 \%$ & $0 \%$ & $0 \%$ & $50 \%$ & $50 \%$ \\
Females & $30.8 \%$ & $38.5 \%$ & $15.4 \%$ & $15.4 \%$ & $34.4 \%$ & $65.6 \%$ & $0 \%$ & $0 \%$ & $23.1 \%$ & $76.9 \%$ \\
\hline
\end{tabular}

Table IV. Correlations of radiological grade with microscopic, microscopic grade s and BMI.

\begin{tabular}{ccccccc}
\hline & \multicolumn{2}{c}{ Macroscopic grade } & \multicolumn{2}{c}{ Microscopic grade } & \multicolumn{2}{c}{ BMI } \\
& Males & Females & Males & Females & Males & Females \\
\hline Radiology Grade & 0.167 & 0.258 & 0.5 & 0.668 & 0.9 & 0.404 \\
\hline
\end{tabular}

BMI: Body Mass Index. Numbers represent (p-values). 

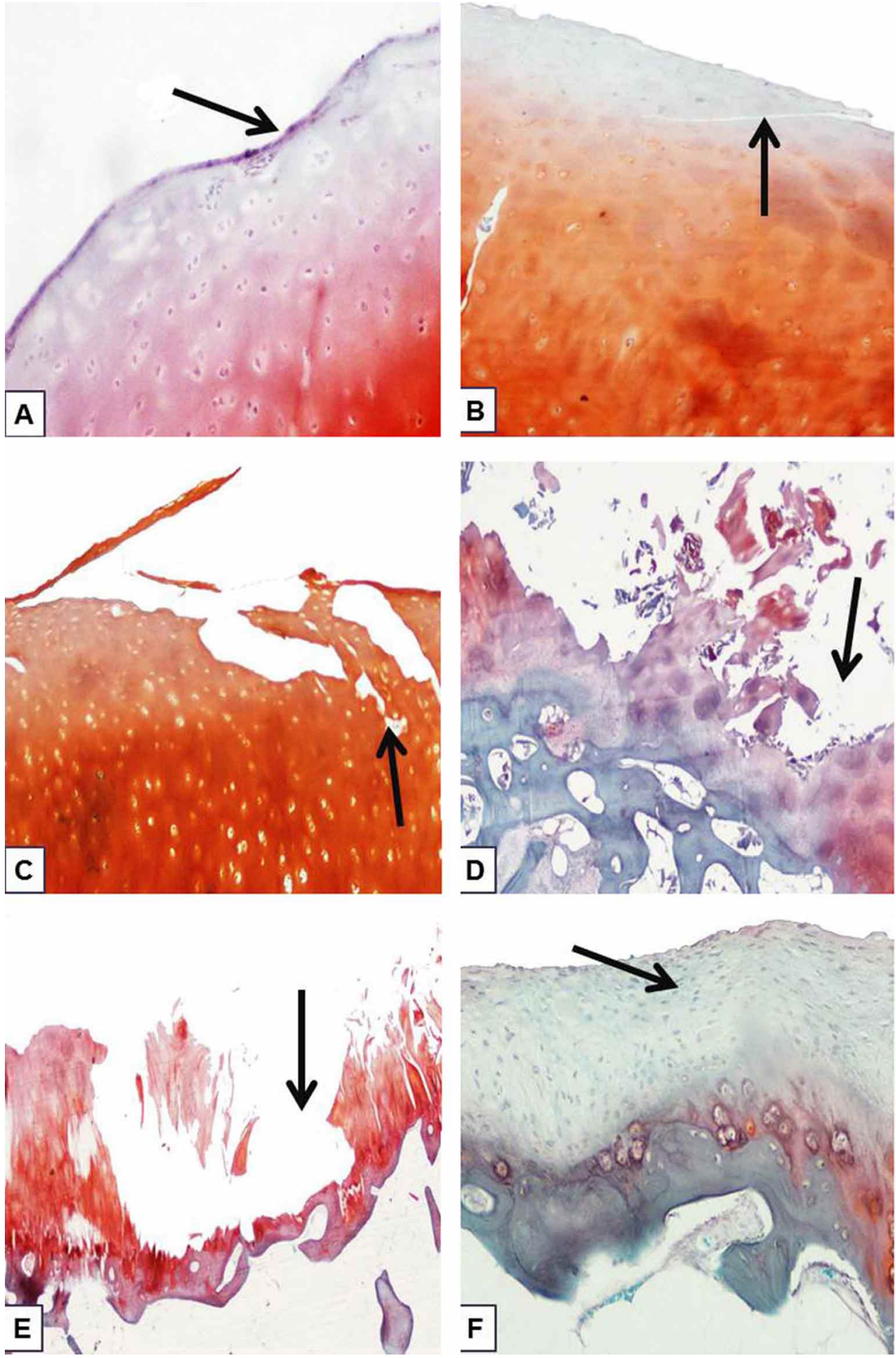

Fig. 3. Histological sections representing different grades of cartilage pathological changes stained with Safranin O/Fast Green A: Surface discontinuity \{macroscopic grade\}. B: Vertical simple fissure \{macroscopic grade\}. C: Complex branching vertical fissures \{macroscopic grade\}. D: Erosion \{macroscopic grade $\}$. E: Denudation \{macroscopic grade $\}$. F: Denudation with reparative tissue on cartilage surface $\{$ macroscopic grade $\}$. Original magnification was $100 \times$.

\section{DISCUSSION}

This study aimed to correlate patients' data (e.g., age, sex and BMI) with the radiological findings and macroscopic and microscopic observations in Saudi OA patients treated with TKA. TKA is the most common surgical treatment for advanced $\mathrm{OA}$ and is indicated if conservative medical therapies have failed (Kehlet \& Thienpont, 2013). TKA is an effective surgical intervention that can provide reliable pain relief and improve functional status and quality-of-life among patients with knee OA. With an increasingly aged population, the TKA utilization rate is expected to increase (Torpy et al., 2011). In Saudi Arabia, TKA is being done in many medical institutions. However, only a few studies have addressed TKA within Saudi Arabia. One such study surveyed patients' attitude toward TKA, while another concluded that TKA improves quality of life in OA patients (Bakhsh, 2006).

Regarding the relationship between the patients' features (age, gender, and obesity) and OA, many investigations have reported how these factors influence the outcome and prognosis of OA patients (Santaguida et al., 2008). These factors remained important determinants for undertaking TKA, even 
after adjusting of other socio-economic factors (Dunlop et al., 2003). Wilkie et al. (2014) reported that knee OA is a highly age- and sex-associated disease, with a considerable impact on the quality of life and significant limitations in social and working life. In Saudi Arabia, the frequency of $\mathrm{OA}$ is likely to increase as a result of an aging population and an increase in the incidence of obesity (Bakhsh).

In this study, the age distribution in our patients was the same as that observed in other studies (Dillon et al., 2006). Aging is one of the most important risk factors for OA, where about $80 \%$ of individuals over the age of 55 years have some radiographic evidence of OA (Jiang et al., 2010). One large community study has shown that the frequency of knee OA among adult Saudi people is $13 \%$, of which $30 \%$ are between 45- and 55-years-old; this proportion doubled by the age of 65 years (Al-Arfaj et al.). In the current study, there was a female predominance, which is consistent with other epidemiological studies (Boyan et al., 2013). However, some studies have suggested that female patients with OA underutilize TKA compared to male patients; often not receiving the surgery until they are at a more advanced stage of the disease (Núñez et al., 2007). The prevalence of OA among women increases dramatically after the age of 50 years, where they have twice the risk of developing bilateral knee OA compared to men (Haq \& Davatchi, 2011). Although little is known about the mechanisms that underlie disparities between male and female OA patients, the onset in females might be related grand multiparity, obesity, lifestyle factors, and the sensitivity of cartilage tissue to sex hormones (Dillon et al.).

In the present study, BMI was abnormal in all patients; obesity class 1 represented $50 \%$ of our cohort, obesity class 2 represented $40 \%$, and morbid obesity $6.7 \%$. Obesity is common in Saudi Arabia, which leads to increasing numbers of TKA (Al-Othaimeen et al., 2007). In accordance with our observations, the association between obesity and OA has been established in a large number of cross-sectional and longitudinal studies. The stress and amount of force on the weight-bearing joints are increased in overweight individuals, which can cause cartilage breakdown, thereby leading to OA. As our study shows, the macroscopic observation of the superior articular surface of tibia and femoral condyle in all patients revealed that most patients had mild scores (1 and 2). However, in the male patients, only scores 1 and 3 were detecetd. In the female patients, the main lesions belonged to score 1 or 2. Macroscopic assessment alone might be insufficient to determine the health of cartilage throughout the knee joint, as indicated by the variability between histological and visual examination. In addition, the OA Research Society International Grading Scale is more detailed for mid-range degradations, providing a score of 2, 3 or 4 depending on the depth of fibrillation, whereas the standard grading scale only allows a grade of 1 for mild fibrillation or 2 for cartilage destruction without visible bone (Pritzker et al.).

Histopathologically, the changes seen in our cases included loss and destruction of articular cartilage, thickening of the subchondral bone, and formation of osteophytes. Because the mechanisms involved in OA initiation and progression remain poorly understood, there is no available intervention to stop or slow the disease advancement (Loeser, 2009). Some previous studies have reported that the start of OA involves thickening and stiffening of subchondral bone, which causes an unequal distribution of transmitted force through the cartilage. The pathogenesis of OA was initially hypothesized as a degenerative process, where injury to the joint surfaces slowly, wears the articular cartilage, and finally exposes the subchondral bone (Malfait, 2016).

In the present study, the radiographic diagnosis of our patients was made according to the American College of Rheumatologists' criteria (Lau et al., 2000). In the present study, all patients were graded as grade $4(73.3 \%)$ or $3(26.7$ $\%)$. Our results are in line with the findings of other studies, which have reported that $\mathrm{OA}$ is typically diagnosed from radiograph images showing narrowing of the joint space and osteophytes, and that all of the components of the knee joint are involved (Malfait). The agreement in the prevalence rates between radiographic and clinical criteria for the diagnosis of OA detected in this study has also been seen by other investigators (Felson \& Zhang, 1998). Also, according to our results, the prevalence of radiographic knee OA increases with increasing age, which would agree with most of the other studies (van Saase et al., 1989). Also, it was reported that the incidence of radiographic knee OA was greater in females than in males, which is consistent with our findings, where most of the female patients showed grade $4(76.9 \%)$.

In conclusion, the outcome of this study will help to understand the pathogenesis of OA and improve decisionmaking relevant to TKA in knee OA patients in Saudi Arabia and elsewhere.

ABD EL-AZIZ, G. S.; GOMAA, W.; HEGAZE, A.; MUSTAFA, H. N. \& AL-HIBSHI, A. Estudio analítico de datos clínico-patológicos de pacientes sauditas con osteoartritis sometidos a artroplastia total de rodilla. Int. J. Morphol., 37(3):1089-1094, 2019,

RESUMEN: La artrosis de rodilla (OA, por sus siglas en inglés) es una enfermedad invalidante común. Los estudios epidemiológicos han revelado diversos factores de riesgo para la $\mathrm{OA}$, que incluyen el sexo, el envejecimiento, la obesidad, las enfermedades profesionales y las enfermedades crónicas. Aquí evalua- 
mos los hallazgos clínicos, patológicos y radiológicos de la OA de rodilla en un subconjunto de pacientes sauditas que fueron sometidos a reemplazo total de rodilla (RTR). La población de estudio incluyó a 30 pacientes saudíes con OA de rodilla que fueron operados por RTR (desde junio de 2014 hasta diciembre de 2015) en el Departamento de Ortopedia, Facultad de Medicina, King Abdulaziz University, Arabia Saudita. Los datos clínicos y radiológicos de los pacientes se obtuvieron de las fichas hospitalarias. Se realizó examen patológico de la superficie articular superior de la tibia extirpada y cóndilos femorales. Se utilizó el análisis Chi-cuadrado de Pearson para probar las diferencias entre las variables en los factores de riesgo asociados. El número de mujeres era mayor que los hombres. El $60 \%$ de los pacientes eran mayores de 60 años [edad media, 59,2 (mujeres) y 61,7 (hombres) años]. Todos los pacientes superaron la obesidad clase 1 , siendo las mujeres más obesas que los hombres. El examen patológico de la superficie articular superior de la tibia y los cóndilos femorales mostraron lesiones con puntaje alto, que fue más evidente en mujeres que en hombres. Los hallazgos radiológicos mostraron que la mayoría de las lesiones eran de alto grado. Los hallazgos de este estudio ayudarán a comprender la patogenia de la OA y mejorarán la toma de decisiones sobre el tratamiento relevante para el RTR en la OA de rodilla en Arabia Saudita y en otros lugares.

PAlabras ClaVe: Osteoartritis; Rodilla; Artroplastía.

\section{REFERENCES}

Al-Arfaj, A. S.; Alballa, S. R.; Al-Saleh, S. S.; Al-Dalaan, A. M.; Bahabry, S. A.; Mousa, M. A. \& Al-Sekeit, M. A. Knee osteoarthritis in AlQaseem, Saudi Arabia. Saudi Med. J., 24(3):291-3, 2003.

Al-Othaimeen, A. I.; Al-Nozha, M. \& Osman, A. K. Obesity: an emerging problem in Saudi Arabia. Analysis of data from the National Nutrition Survey. East Mediterr. Health J., 13(2):441-8, 2007.

Bakhsh, T. M. Results of total knee replacement using a cemented stemmed prosthesis. Saudi Med. J., 27(5):661-6, 2006.

Boyan, B. D.; Tosi, L. L.; Coutts, R. D.; Enoka, R. M.; Hart, D. A.; Nicolella, D. P.; Berkley, K. J.; Sluka, K. A.; Kwoh, C. K.; O'Connor, M. I.; et al. Addressing the gaps: sex differences in osteoarthritis of the knee. Biol. Sex Differ, 4(1):4, 2013.

Dillon, C. F.; Rasch, E. K.; Gu, Q. \& Hirsch, R. Prevalence of knee osteoarthritis in the United States: arthritis data from the Third National Health and Nutrition Examination Survey 1991-94. J. Rheumatol., 33(11):2271-9, 2006

Dunlop, D. D.; Song, J.; Manheim, L. M. \& Chang, R. W. Racial disparities in joint replacement use among older adults. Med. Care, 41(2):288-98, 2003.

Felson, D. T. \& Zhang, Y. An update on the epidemiology of knee and hip osteoarthritis with a view to prevention. Arthritis Rheum., 41(8):134355, 1998.

Haq, S. A. \& Davatchi, F. Osteoarthritis of the knees in the COPCORD world. Int. J. Rheum. Dis., 14(2):122-9, 2011.

Hongbin, W.; Jingyuan, D.; Linyun, C. \& Yuming, D. Carboxymethylated chitin reduces MMP-1 expression in rabbit ACLT osteoarthritic cartilage. Ann. Rheum. Dis., 63(4):369-72, 2004.

Jiang, D.; Zou, J.; Huang, L.; Shi, Q.; Zhu, X.; Wang, G. \& Yang, H. Efficacy of intra-articular injection of celecoxib in a rabbit model of Osteoarthritis. Int. J. Mol. Sci., 11(10):4106-13, 2010.

Kang, Q. K.; LaBreck, J. C.; Gruber, H. E. \& An, Y. H. Histological Techniques for Decalcified Bone and Cartilage. In: An, Y. H. \& Martin,
K. L. (Eds.). Handbook of Histology Methods for Bone and Cartilage. New York, Springer Science+Business Media, 2003. pp.209-19.

Kehlet, H. \& Thienpont, E. Fast-track knee arthroplasty -- status and future challenges. Knee, 20 Suppl. 1:S29-33, 2013.

Kellgren, J. H. \& Lawrence, J. S. Radiological assessment of osteo-arthrosis. Ann. Rheum. Dis., 16(4):494-502, 1957.

Kingsbury, S. R.; Hensor, E. M.; Walsh, C. A.; Hochberg, M. C. \& Conaghan, P. G. How do people with knee osteoarthritis use osteoarthritis pain medications and does this change over time? Data from the Osteoarthritis Initiative. Arthritis Res. Ther., 15(5):R106, 2013.

Loeser, R. F. Aging and osteoarthritis: the role of chondrocyte senescence and aging changes in the cartilage matrix. Osteoarthritis Cartilage, 17(8):971-9, 2009.

Malfait, A. M. Osteoarthritis year in review 2015: biology. Osteoarthritis Cartilage, 24(1):21-6, 2016.

Murphy, L. \& Helmick, C. G. The impact of osteoarthritis in the United States: a population-health perspective: A population-based review of the fourth most common cause of hospitalization in U.S. adults. Orthop. Nurs., 31(2):85-91, 2012.

Núñez, M.; Núñez, E.; del Val, J. L.; Ortega, R.; Segur, J. M.; Hernández, M. V.; Lozano, L.; Sastre, S. \& Maculé, F. Health-related quality of life in patients with osteoarthritis after total knee replacement: factors influencing outcomes at 36 months of follow-up. Osteoarthritis Cartilage, 15(9):1001-7, 2007.

Pritzker, K. P.; Gay, S.; Jimenez, S. A.; Ostergaard, K.; Pelletier, J. P.; Revell, P. A.; Salter, D. \& van den Berg, W. B. Osteoarthritis cartilage histopathology: grading and staging. Osteoarthritis Cartilage, 14(1):1329, 2006

Santaguida, P. L.; Hawker, G. A.; Hudak, P. L.; Glazier, R.; Mahomed, N. N.; Kreder, H. J.; Coyte, P. C. \& Wright, J. G. Patient characteristics affecting the prognosis of total hip and knee joint arthroplasty: a systematic review. Can. J. Surg., 51(6):428-36, 2008.

Torpy, J. M.; Lynm, C. \& Golub, R. M. JAMA patient page. Knee replacement. JAMA, 305(8):844, 2011.

van Saase, J. L.; van Romunde, L. K.; Cats, A.; Vandenbroucke, J. P. \& Valkenburg, H. A. Epidemiology of osteoarthritis: Zoetermeer survey. Comparison of radiological osteoarthritis in a Dutch population with that in 10 other populations. Ann. Rheum. Dis., 48(4):271-80, 1989.

Vignon, E.; Bejui, J.; Mathieu, P.; Hartmann, J. D.; Ville, G.; Evreux, J. C. \& Descotes, J. Histological cartilage changes in a rabbit model of osteoarthritis. J. Rheumatol., 14 Spec No:104-6, 1987.

Wilkie, R.; Phillipson, C.; Hay, E. M. \& Pransky, G. Anticipated significant work limitation in primary care consulters with osteoarthritis: a prospective cohort study. B. M. J. Open, 4(9):e005221, 2014.

Zeni, J. A. Jr. \& Snyder-Mackler, L. Clinical outcomes after simultaneous bilateral total knee arthroplasty: comparison to unilateral total knee arthroplasty and healthy controls. J. Arthroplasty, 25(4):541-6, 2010.

Corresponding author:

Dr. Hesham N. Mustafa

Department of Anatomy

Faculty of Medicine

King Abdulaziz University

PO Box 80205

Jeddah 21589

SAUDI ARABIA

Email: hesham977@hotmail.com

Received: 08-02-2019

Accepted: 12-04-2019 